\title{
THE INFORMATION SERVICES VIEW
}

\author{
Matt Germonprez \\ Information Systems, College of Business \\ University of Wisconsin - Eau Claire \\ Eau Claire, WI U.S.A. \\ Dirk Hovorka \\ Information Systems, Leeds School of Business \\ University of Colorado - Boulder \\ Boulder, CO U.S.A.
}

\section{ABSTRACT}

The information services view engenders a conceptual shift from the provision of defined and predetermined services to an environment that enables users to select and integrate information services in the ongoing creation and recreation of unique information systems. The information services view (ISV) conceptualizes technology as an ensemble of facilities that perform an action or function on the users' behalf. The vision of ISV is the realization of user-enabled, real-time production of ad hoc information systems.

The ISV specifies that users of services are intelligent actors who are able to compute seamlessly across contexts and recognizes that services developers may not know how their services are going to be used but instead develop a reflective environment where users' thinking and redesign is supported. The ISV represents a dramatic shift in design from provision of a fixed, externally controlled service set to design of "a space of potential for human concern and action" (Winograd and Flores 1986, p. 37).

The ISV is a supplementary view of technology (Orlikowski and Iacono 2001) which focuses on the realization of flexible service development that engages users as secondary developers for which the technology bar was previously unacceptably high. Although new configurations for information systems can result from versioning or specific design changes, the evolutionary trajectory and evolving nature of systems is commonly the result of user-initiated mutability (Gregor and Jones 2007) or tailoring (Germonprez et al. 2007). The ISV embraces processes by which developers/providers expose information and allow user-initiated selection and configuration of services that fit "the idea of the arising of something from out of itself, or emergent properties, and behavior" (Gregor and Jones 2007, p. 326).

Please use the following format when citing this chapter:

Germonprez, M., and Hovorka, D., 2008, in IFIP International Federation for Information Processing, Volume 267, Information Technology in the Service Economy: Challenges and Possibilities for the $21^{\text {st }}$ Century, eds. Barrett, M., Davidson, E., Middleton, C., and DeGross, J. (Boston: Springer), pp. 365-366. 
The ISV distinguishes between the initial design and the ways of doing design and requires that attention be paid to the different experiences, perceptions, intentions, and goals that the user will use to recreate the design of the information system. It also aims to create a phenomenological potential for action in which the user tailors the information system and develops uses in new contexts or for new tasks (Germonprez et al. 2007). The ISV moves away from a dominant approach in systems design to over-engineer the information technology artifact through a restricted set of data structures, interfaces, and reporting systems, so that a limited range of work practices are allowed. By standardizing information gathering and presentation, many approaches produce and reproduce error by restricting the ability of users to reflexively and skillfully adjust their practices and computing systems to support changing goals, use patterns, and tasks. The ISV requires the support of classes of tasks, use patterns, recognizable conventions and components, and metaphors that the end user reflects on and engages during use. The ISV suggests that it is incumbent on designers to build a flexible, holistic picture of what services are and how they can create novel recombinant information systems.

\section{References}

Germonprez, M., Hovorka, D., and Collopy, F. 2007. "A Theory of Tailorable Technology Design," Journal of the Association for Information Systems (8:6), pp. 315-367.

Gregor, S., and Jones, D. 2007. "The Anatomy of a Design Theory," Journal of the Association for Information Systems (8:5). pp. 312-335.

Orlikowski, W., and Iacono, C. 2001. "Desperately Seeking the 'IT' in IT Research -A Call to Theorizing the IT Artifact," Information Systems Research (12:2), pp. 121-134.

Winograd, T., and Flores, F. 1986. Understanding Computers and Cognition: A New Foundation for Design, Norwood, NJ: Ablex Publishing Corporation.

\section{About the Authors}

Matt Germonprez is an assistant professor of Information Systems at the University of Wisconsin - Eau Claire. He received his Ph.D. at the University of Colorado in Boulder in 2002. His research interests are in the domain of human-computer interaction with a secondary interest in Information Systems theory. He is a member of IFIP 8.2, ACM, and AIS, and currently serves on the executive council for the AIS Special Interest Group for Human-Computer Interaction. He has published work in Journal of the AIS, Communications of the AIS, Organization Studies, International Journal of IT Standards and Standardization Research, Designing Ubiquitous Information Environments: Socio-Technical Issues and Challenges (IFIP 8.2), and Information Systems Research: Relevant Theory and Informed Practice (IFIP 8.2). Matt can be reached at germonr@, uwec.edu.

Dirk S. Hovorka is currently a Scholar in Residence at the Leeds School of Business, University of Colorado at Boulder. He attended Williams College in Massachusetts for his B.A., holds an M.S. in Geology and an M.S. in Interdisciplinary Telecommunications, and received his Ph.D. in Information Systems from the University of Colorado. His research includes the philosophical foundations of IS research, the development of design theory, the evolving role of information systems in science, and the influences of social networks on knowledge management. He has published research in the Journal of the AIS, European Journal of Information Systems, Communication of the AIS, Business Agility and Information Technology Diffusion (IFIP 8.6), and Perspectives on Information Management: Setting the Scene. Dirk can be reached at dirk.hovorka@ colorado.edu. 